\title{
Ultrastructural Pathology of Golgi Apparatus of Nerve Cells in Human Brain Edema
}

\author{
Orlando J Castejón*1 and Haydee Viloria de Castejón ${ }^{2}$ \\ ${ }^{1}$ Faculty of Medicine, Zulia University and Institute of Clinical Neuroscience, Venezuela \\ ${ }^{2}$ Castejon Foundation, Zulia University and Institute of Clinical Neuroscience, Venezuela
}

Received: 糊 August 20, 2018; Published: 毕 August 31, 2018

*Corresponding author: Orlando J Castejón, Instituto de Investigaciones Biológicas "Drs. Orlando Castejón and Haydee Viloria de Castejón”. Facultad de Medicina. Universidad del Zulia. Apdo. 526. Maracaibo, Venezuela

Keywords: Golgi Apparatus; Nerve Cells; Brain Edema; Familial Amyotrophic; Hydrocephalus; Alzheimer's Disease; Pathogenesis; Marked Dilation

Trans Golgi Network; Leptomeningeal Limphoma

\section{Introduction}

Tani et al. [1] earlier described fenestrae in Golgi apparatus and endoplasmic reticulum cisternae of human brain tumors. Tougard et al [2] found short discontinuous Golgi cisternae in tumoral prolactin cells in culture. Petito and Pulsinelli [3] described transformation of Golgi apparatus into large clusters of small vesicles without cisterns in cortical and striatal neurons following cerebral ischemia. Petito [4] showed transient swelling of Golgi apparatus in perineuronal oligodendroglial cells in areas of ischemic neuronal necrosis. Blanchette-Mackie [5] found abnormal accumulation of cholesterol at the level of Golgi complex in fibroblasts of patients with Type-C Niemann-Pick disease. Palacios [6] observed betaamylod precursor protein localization in the Golgi apparatus of normal and axotomized rat neurons. Lucassen et al. [7] reported increasing size of Golgi apparatus in human supraventricular nucleus neurons in aging and in Alzheimer's disease. Pathological disorders of Golgi apparatus have been also described by Ghadially [8] in a variety of non-nervous diseases involving altered secretory activity (albuminemia, lipoproteinemias), cell surface pathology (cancer) and viral diseases.

Morré [9] reported atrophic changes and discrete or marked dilation, fragmentation and partial disappearance of Golgi stacked cisternae in human congenital hydrocephalus. Salehi et al. [10] found smaller Golgi apparatus in Alzheimer's disease. Stieber et al. [11] described atrophic and fragmentation of Golgi apparatus in Alzheimer's disease. Fragmentation of Golgi apparatus of human spinal motor neurons has been also reported by Tascos et al. [12] in amyotrophic lateral sclerosis, leptomeningeal limphoma, leukemia and multiple myeloma. In global brain ischemia and reperfusion, the Golgi cisternae were reported by Rafols et al. [13] as shorter and widely dilated. The Golgi complex was fragmented into vacuoles, membranous whorls, and exhibiting dense aggregates of coalescent smooth vesicles. Xu et al. [14] demonstrated that activation of endogenous protein kinase $\mathrm{C}$ regulates the formation of Golgi secretory vesicles in Alzheimer's disease. Harada et al. [15] reported Golgi vesiculation and lysosome dispersions in cells lacking cytoplasm dynein. Mourelatos et al. [16] and Fujita et al. [17-19] reported fragmentation of Golgi apparatus in patients with familiar amyotrophic lateral sclerosis, and in transgenic mouse expressing mutant $\mathrm{Cu}, \mathrm{Zn}$ superoxide dismutase. Greenfield et al. [20] described the generation and accumulation of beta amyloid peptides in the trans-Golgi network and vesicles. Elyaman et al. [21] reported Involvement of glycogen synthase kinase-3beta and tau phosphorylation in neuronal Golgi disassembly.

Sakurai et al. [22] observed fragmentation of Golgi apparatus in ballooned neurons from patients with corticobasal degeneration and Creutzfeldt-Jacob disease. Takamine et al. [23] described normal-looking patterns, fragmentation, reduction in number, and aggregation of Golgi complex in human olivary hypertrophy. Stieber et al. [24] reported in Alzheimer's disease the Golgi apparatus appeared fragmented in the form of small, round, disconnected and dispersed elements. Dubelaar et al. [25] found increased metabolic activity in the nucleus basalis of meynert neurons in elderly individuals with mild cognitive impairment as indicated by the size of Golgi apparatus. Yaguchi et al. [26] reported reduction of Golgi apparatus in X-linked spinal and bulbar muscular atrophy. Yoshiyama et al. [27] found fragmentation and atrophy of Golgi apparatus in tau-induced degeneration in astrocytes. Sahashi et al. [28] suggested that Golgi apparatus is the target organelle in a subset of myopathies. Moldovan and Moldovan [29] considered that Golgi membranes are exquisitely sensitive to reactive oxygen species (ROS).

Stieber et al. [30] described dispersion of Golgi apparatus and dysfunction of secretory pathway in familial amyotrophic lateral sclerosis. Hayashi and Abe [31] reported involvement of 
Golgi apparatus in apoptotic cell death after ischemia. Grieb et al. [32] described expansion of Golgi apparatus following intra cerebro-ventricular injection of streptozotocin in rats. Fujita and Okamoto [33] also reported Golgi apparatus fragmentation in amyotrophic lateral sclerosis and related this organelle with neuronal degeneration. Ferre et al. [34] observed mitochondrial, endoplasmic reticulum and Golgi apparatus damage in late onset cerebellar and sensory ataxia in mice with inactivated abcd1 gene. Dubelaar et al. [25] related large Golgi apparatus with increased metabolic activity of Meynert neurons in elderly individuals with mild cognitive impairment. Fujita et al. [36] found fragmentation of Golgi apparatus of nigral neurons with alpha-synuclein-positive inclusions in patients with Parkinson's disease. Snigirevskaia et al. [37] suggested a probable involvement of Golgi complex in water transport. Yaguchi et al. [26] reported reduction of the size of the Golgi apparatus of spinal anterior horn cells in patients with $\mathrm{X}$-linked spinal and bulbar muscular atrophy.

Gonatas et al. [38] postulate that Golgi fragmentation is an early and probably irreversible lesion in neurodegeneration, caused by a variety of mechanisms that may "trigger" apoptosis. Schaefer et al. [39] postulate that motor axons critically depend on axonal tubulin routing from the Golgi apparatus, a process that involves the tubulinspecific chaperone (TBCE) and possibly other tubulin chaperones. Nakagomi et al. [40] found that Golgi fragmentation and dispersal precede neuronal cell death triggered by excitotoxins, oxidative/ nitrosative insults, or ER stress. These findings implicated the Golgi as a sensor of stress signals in cell death pathways. Fujita et al. [41] described morphological changes of Golgi apparatus in adult rats after facial nerve injuries. Baloyannis [42] postulates that alteration of GA may be associated with alterations of microtubules, impaired protein trafficking, and dendritic, spinal, and synaptic pathology, since protein trafficking plays an essential role in the threedimensional organization of the dendritic arbor and in the integrity of the synaptic components.

Jaarsma and Hoogenraad [43] emphasized the role of cytoplasmic dynein and its regulatory proteins in Golgi pathology in nervous system disorders Kaneko et al. [44] found that Golgi complex fragmentation and reelin dysfunction are key contributors to neuronal cell death in the early stage of epilepsy pathophysiology, thereby representing as novel disease biomarkers, as well as potent therapeutic targets for epilepsy. Antón-Fernández et al. [45] support the idea that the progressive accumulation of phosphotau is associated with structural alterations of the GA including fragmentation and a decrease in the surface area and volume of GA elements. These alterations likely impact the processing and trafficking of proteins, which might contribute to neuronal dysfunction in Alzheimer disease. In the present review we describe the ultrastructural pathobiology of Golgi apparatus in edematous cortical neurons and neuroglial cells of patients with congenital hydrocephalus, vascular anomaly, brain tumors and brain trauma. The important role of Golgi complex as an early marker of nerve cell injury, degeneration, and cell death is emphasized.

\section{Golgi Complex Alterations in Congenital Hydrocephalus}

In some severely edematous neurons observed mainly in congenital hydrocephalus and hydrocephalus associated to
Arnold-Chiari malformation small vesicular type Golgi complexes and apparently atrophic ones are observed, characterized by fragmentation and partial or total disappearance of Golgi cisternae, and presence of numerous Golgi vesicles. In such cases damage of plasma membrane and swollen mitochondria are also found Castejón et al. [46] (Figure 1). Atrophic Golgi complexes have been also reported in non-nervous cells, such as synovial cells in osteoarthritis, enucleated amoeba, and hepatocytes subjected to a variety of toxic influences Ghadially [8]. Transformation of Golgi apparatus into large clusters of small vesicles was found by Petito and Pulsinelli [4] following cerebral ischemia in rats. Small Golgi apparatus has been also reported by Salehi et al. [16] in tuberomamillary neurons in patients with Alzheimer's disease. Golgi vesiculation and lysosome dispersion have been observed in cells lacking cytoplasm dynein, a microtubule-based motor protein responsible for movement of membrane organelles [15].
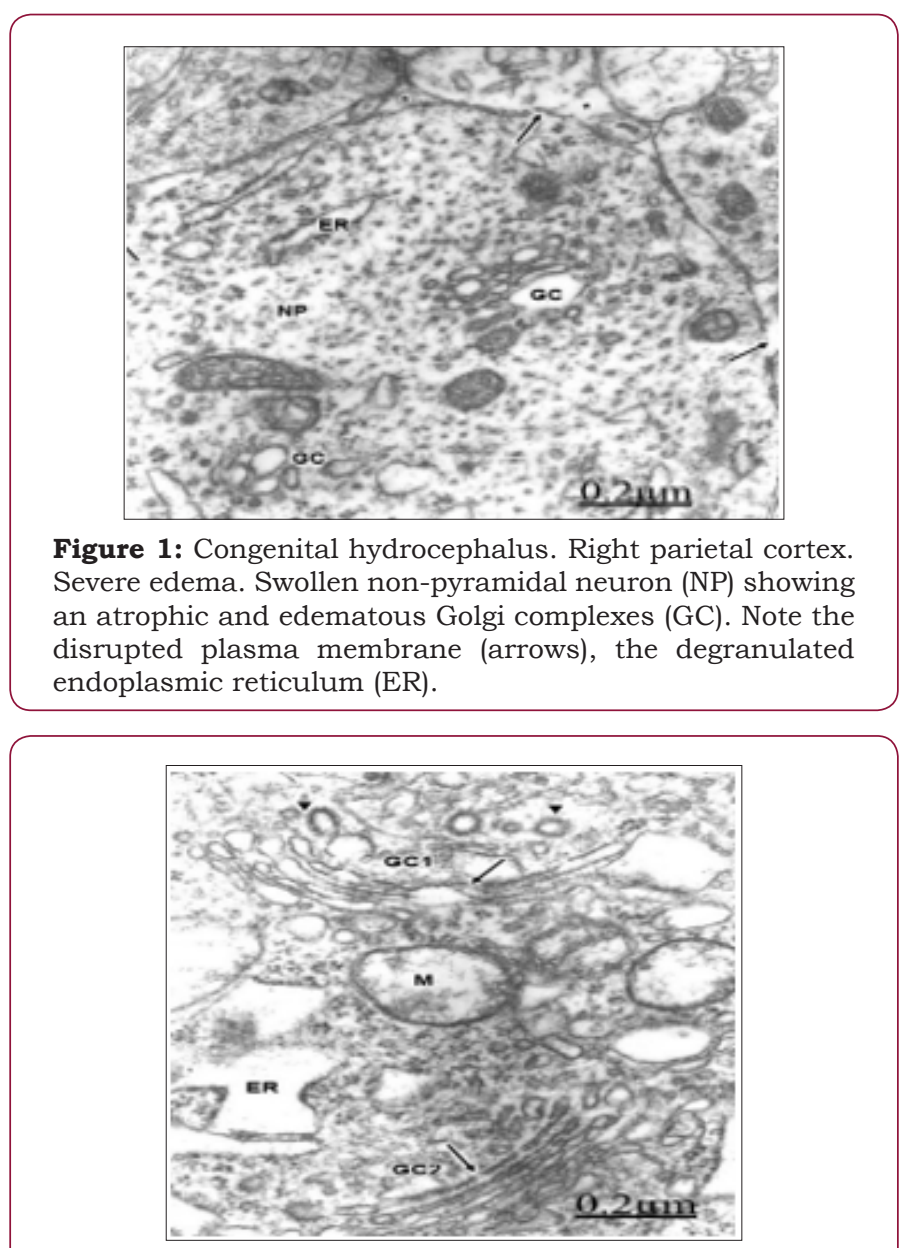

Figure 2: Congenital hydrocephalus. Right parietal cortex. Golgi vacuolated complexes (GC1 and GC2) with normal or dilated endoplasmic sacs (long arrow) and swollen mitochondria (M), Note the numerous small and medium Golgi vesicles and coated vesicles (arrowheads) arising from the trans-Golgi complex compartment. Note the lacunar enlargement of rough endoplasmic reticulum (ER).

As illustrated in Figure 2, a swollen and fragmented Golgi apparatus is observed coexisting with lacunar dilation of rough endoplasmic reticulum canaliculi. A disruption of the Golgi elements is seen with displacement of intact or fragmented Golgi endoplasmic sacs, presence of small, medium and large, clear and dense Golgi vesicles and enlarged Golgi vacuoles. Such image suggests 
fragmentation of the stacked Golgi cisternae, increased secretory activity in the trans-Golgi compartment, and morphological signs of increased number of Golgi and chlatrin-coated vesicles with augmented intra cytoplasmic vesicular traffic [47].

\section{Golgi Complex Abnormalities in Vascular Anomaly}

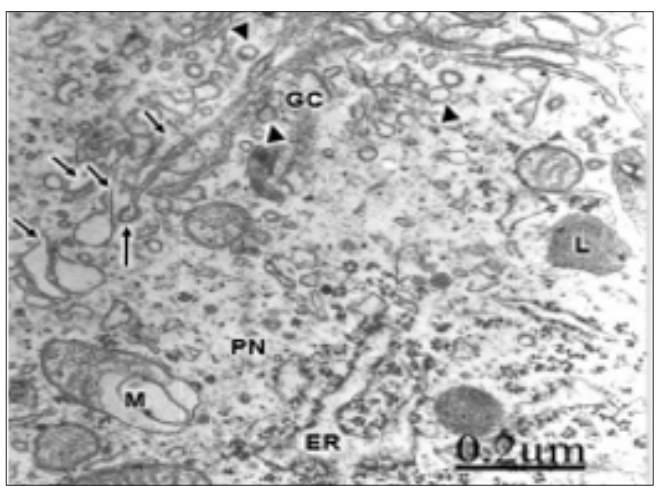

Figure 3: Anomaly of anterior cerebral artery. Right parietal cortex. Non-pyramidal neuron displaying a hypertrophic Golgi complex (GC) with fragmented and vacuolized Golgi stacked cisternae (short arrows), and enlargement of Golgi vesicles at the cis- and trans Golgi compartments (arrowheads).

In patients with an anomaly of anterior cerebral artery, a large hypertrophic Golgi complex is observed in pyramidal nerve cells (Figure 3), with fragmentation of Golgi stacked cisternae and increased formation of uncoated and coated Golgi vesicles [48].

\section{Golgi Complex Pathology in Brain Tumors}

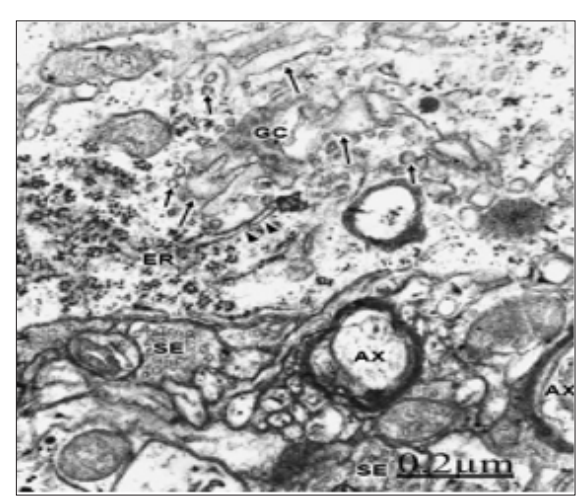

Figure 4: Cystic craniopharyngioma. Right frontal cortex. Non-pyramidal neuron exhibiting a swollen and frafmented Golgi complex (GC) with dense, widened and fragmented Golgi stacked cisternae (long arrows), and formation of numerous and dense clear and dense Golgi vesicles. vesicles (short arrows).

Note: the transitional endoplasmic reticulum (arrowheads) between the rough endoplasmic reticulum (ER) and the damage Golgi complex. A degenerated myelinated axon (AX) and shrunken synaptic endings (SE) are observed in the neighboring neuropil.

In brain tumors enlargement and fragmentation of moderately dense Golgi stacked cisternae is found (Figure 4). In addition, numerous clear and dense small Golgi vesicles are observed in the cis- and trans-Golgi compartments, indicating increased secretory activity of Golgi apparatus in tumor cells. Some electron micrographs of brain tumors show changes in the Golgi apparatus architecture, displaying dilated Golgi cisternae in perpendicular orientation. Besides, dense core vesicles and dense clathrin-coated vesicles are observed in the Golgi region, and migrating throughout the cytoplasm [49-54] (Figure 4). In brain trauma, a large and vacuolized hypertrophic Golgi complex is seen in non- pyramidal nerve cells (Figure 5). Fenestration of Golgi cisternae were earlier reported by Tani et al. [1] in human brain tumors. Discontinuous flat Golgi cisternae were also earlier reported by Tougard et al. [2] in tumoral prolactin cells in culture. Golgi fragmentation have been also described by Stieber [24,30], Mourelatos et al [16], Fujita et al. [18-19], and Dubelaar et al. [25] in amyotrophic lateral sclerosis, Alzheimer's disease and aging.

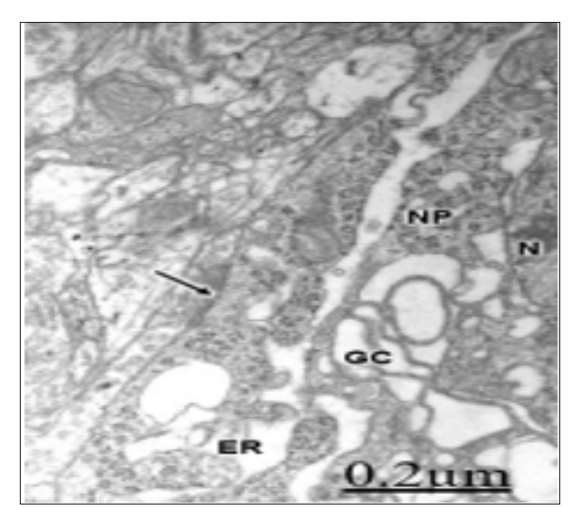

Figure 5: Brain trauma. Subdural hematoma. Left parietal cortex. Non-pyramidal neuron (NP) showing lacunar enlargement of Golgi complex (GC), and endoplasmic reticulum (ER) The nucleus $(\mathrm{N})$, and an axosomatic synaptic contact (arrow) also are distinguished.

These authors suggest that alteration of Golgi apparatus is involved in the pathogenesis of these diseases, and that the fragmentation of this organelle may be associated with functional and structural impairments of axons and presynaptic terminals. A similar process has been also reported in amyotrophic lateral sclerosis, in asymptomatic and symptomatic transgenic mice expressing the G93A mutation of the gene of the human $\mathrm{Cu}, \mathrm{Zn}$ superoxide dismutase, and in cells treated with microtubuledepolimerizing drugs [12]- Stieber et al. [11], Fujita et al.[41]Rafols et al. [13] have also reported dilatation and fragmentation of Golgi apparatus in global brain ischemia and reperfusion in neurons selective vulnerable to death. Sakurai et al. [50] showed fragmentation of Golgi complex in the ballooned neurons in patients with corticobasal degeneration and Creutzfeldt- Jacob disease. Fragmentation, reduced in number and aggregation of Golgi apparatus around the nucleus was reported by Takamine et al. [23] in human olivary hypertrophy. According to Hu et al. [14], Golgi fragmentation is associated with ceramide-induced cellular effects.

Marked enlargement of the Golgi stacked cisternae and the rough and endoplasmic reticulum (ER) is found. In areas of severe traumatic brain edema and subdural hematoma vacuolated and 
fragmented Golgi complex in nonpyramidal nerve cells are observed (Figure 6). At the level of oligodendroglila cells the Golgi apparatus appear dilated and with a curved configuration of endoplasmic sacs (Figure 7). At the capillary wall, the endothelial cells display enlarged and dilated hypertrophic Golgi complex (Figure 8). A caveolae intracellularis (arrowhead) is observed at the endothelial cell luminal membrane. Some coated and uncoated vesicles and vacuoles are internalized (small arrows) towards the hypertrophic Golgi complex (GC). Note that other endothelial vacuoles (asterisks) follow a transcapillary route to the swollen basement membrane (BM). Some vesicles appear surrounding a multivesicular body (MB). Note the hydropic changes of Golgi endoplasmic sacs and vacuoles. The capillary lumen (L) also is noted.

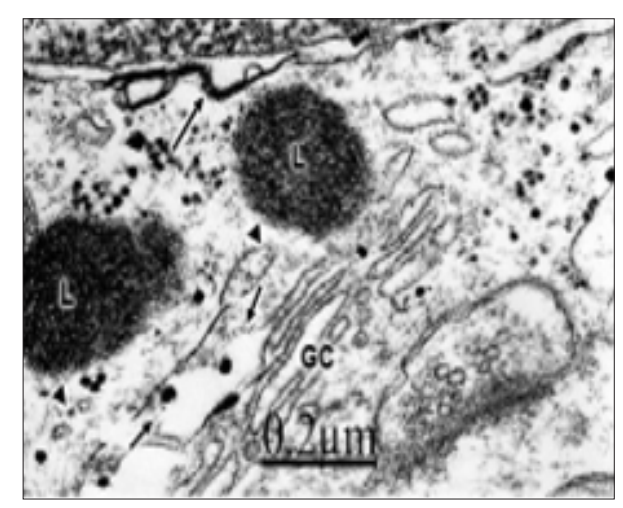

Figure 6: Brain trauma. Subdural hematoma. Vacuolated and fragmented Golgi complex (GC). Note the disrupted Golgi cisternae (small arrows). The long arrow points out the necrotic nuclear envelope. An axosomatic synaptic ending also is seen at the lower right angle of the figure.

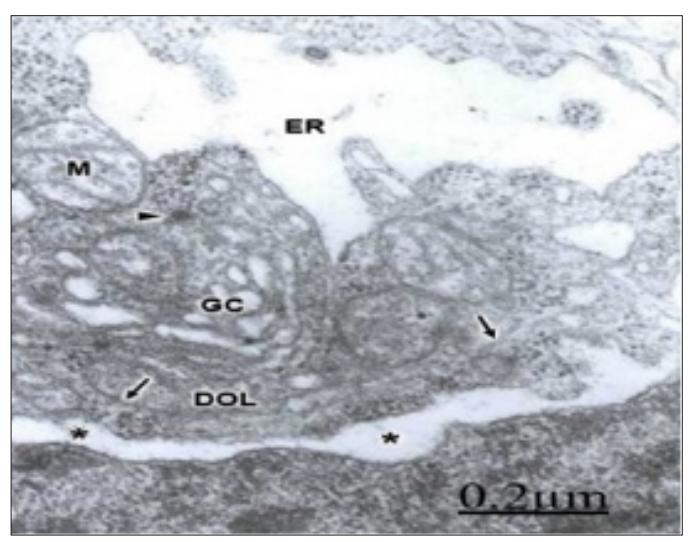

Figure 7: Brain trauma. Right epidural hematoma. Severe edema. Right temporal cortex. Dense and hydropic interfascicular oligodendrocyte (DOL) showing hydropic changes of nuclear envelope $\left({ }^{*}\right)$, swollen mitochondria (M), dilated Golgi complex (GC), and lacunar enlargement of rough endoplasmic reticulum (ER). Microtubules (arrows) and a dense cored vesicle (arrowhead) also are seen.

The morphological data examined in vascular anomaly, brain tumor and trauma suggest an hiperactivity of Golgi cisternae secretory cargo in the cist-trans direction, and subsequently an increased vesicular transport throughout the cytoplasm. The enlargement of the Golgi endoplasmic sacs coexists with dilated rough endoplasmic reticulum and perinuclear cisterns suggesting a continuous intracellular microcirculatory system for edematous fluid. Enlargement of Golgi apparatus have been also found by Lucassen et al. [7] in human supraoptic and paraventricular neurons in Alzheimer's disease and aging. Similar findings were reported by Grieb et al. [32] following intracerebral injection of streptozoticin. In areas of very severe edema, focal necrosis of Golgi smooth membranes, nuclear envelope and plasma membrane is also encountered. It is important to emphasize that in moderately edematous regions some neuronal populations show only enlargement of Golgi stacks without fragmentation. The Golgi apparatus maintaining its general architecture. In acute phase response of inflammation, the Golgi complex reacts in nonnervous cells with enlargement of Golgi stacks [51] but retain their organizational compartment.

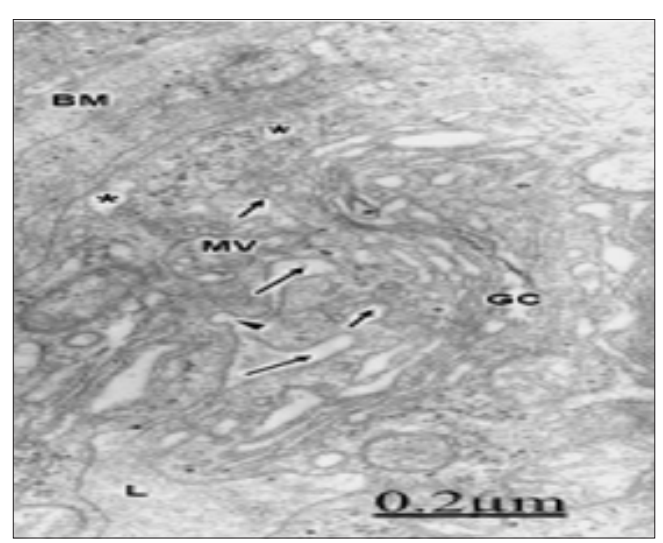

Figure 8: Brain trauma. Contusion of frontal region. Right frontal cortex. Deep invaginations of the endothelial cell luminal membrane (long arrows) are formed at the endothelial peripheral cytoplasm.

In the damaged Golgi complexes presumably, we are dealing with two successive pathological events, involving first: enlargement of Golgi complex as an early reaction to anoxicischemia conditions, and second: loss of Golgi architecture, then progressively leading to Golgi fragmentation and Golgi membrane necrosis. Since in our studies we are mainly working with cortical biopsies of living patients we cannot establish by ethical reasons if disassembly and reassembly of Golgi fragments occur in nerve cells as observed in normal mitotic cells [52]. We do not know whether disorganization of Golgi complex is a reversible process or a stage prior to reorganization, as described by Bainton et al. [53] in macrophages during phagocytosis of immobile immune complexes. Swollen mitochondria, fragmented microtubules, multivesicular bodies, and lysosomes are observed surrounding the Golgi regions. As illustrated in all electron micrographs examined in our laboratory, the disorders of the Golgi apparatus are accompanied in most cases by fragmentation of nerve cell plasma membrane, degenerated myelinated axons, and swollen and degenerated presynaptic endings, suggesting that Golgi complex alteration could be considered as an early marker of nerve cell injury and degeneration $[13,38,54]$.

There is apparently an interference with the constitutive and regulated secretions of proteins in nerve cells. The ischemic and 
anoxic conditions of nerve tissue in these pathological entities would alter the post-translational modifications of proteins within the Golgi apparatus. The Golgi vesicles that are observed budding off from the Golgi apparatus are related with the transfer of proteins toward the plasma membrane (constitutive secretion). Consequently, the insertion of integral membrane proteins, including ion channels and receptor molecules, into the plasma membrane is disturbed causing fragmentation and necrosis of the plasma membrane. This altered process seems to occur also simultaneously in the smooth Golgi membranes. The process of regulated secretion, which is acutely stimulated by external factors such as trauma and tumors is also altered [56]. In addition, the increased levels of calcium in ischemic conditions open the voltage-dependent calcium channels and increase the regulated secretion process [58]. Swollen and fragmented Golgi complexes are observed also in capillary endothelial and pericyte cells, perineuronal and pericapillary astrocytes, perineuronal and interfascicular oligodendrocytes, microglial cells and invading non-nervous inflammatory and phagocytic cells, suggesting that Golgi complex alteration is a general pathobiological phenomenon against a noxious stimulus [8].

\section{The Relationship of Golgi Complex Pathology and Synaptic Degeneration}

The disturbance of the Golgi complex is apparently related with the neuronal, axonal and synaptic degeneration $[17,18,19]$. As earlier proposed by André [59] and Gray [60] some synaptic vesicles could be originated from the Golgi complex. These Golgi vesicles, containing the enzymes that catalyze the synthesis of some neurotransmitters, are then transported through the neuronal cytoplasm and axonal process to the release sites at the nerve endings. Therefore, an altered of both, the Golgi complex, and intracytoplasmic vesicular traffic could induce presynaptic vesicular degeneration. The altered constitutive and regulated secretion pathways should induce an over-all alteration of the following events: protein insertion into presynaptic membrane, exocitotic process, retrieval by endocytosis, and the formation of mature synaptic vesicles [56].

Numerous electron micrographs support our proposed hypothesis on Golgi complex pathology and degenerated synaptic endings [58]. It should be considered in addition, that the altered exocytotic process at the presynaptic ending would be coexisting with an irregular movement of vesicles from the endoplasmic reticulum to the Golgi complex, as an expression of a general pathobiological process. The disturbed budding, docking, and fusion processes of synaptic vesicles at the level of presynaptic membrane would be the result of an altered budding off vesicular process at the Golgi complex and a disturbed intracytoplasmic and axonal vesicular traffic. The presence of coated vesicles in both, the Golgi region and in the presynaptic endings implies that a clathrin coated vesicular intracytoplasmic traffic exists, and that a clathrin vesicular formation process occurs at the presynaptic endings in the recycling process of synaptic vesicles.

\section{The Golgi Complex Alteration in Brain Ischemia}

The anoxic-ischemic conditions of nerve tissue induce edema of Golgi complex compartments [4].The increased levels of calcium ion during ischemia [58] seems to be responsible for such edema, due to opening of voltage-dependent calcium channels and by release from the storage sites in the endoplasmic reticulum, particulary under the influence of IP3 and the ryanodine receptor, an endoplasmic reticulum calcium-release channel, that is opened by the elevated cytoplasmic calcium, hence giving rise to complex patterns of intracellular calcium signaling, responsible by the enlargement of Golgi smooth stacked cisternae and vesicles. In brain edema and ischemia there is also a process of lipid peroxidation $[58,61]$ and membrane damage due to the release of arachidonic acid, free radical's Siesjo et al. [62], and nitric oxide- This lipid peroxidation process explains the damage of smooth Golgi membrane, nuclear envelope and plasma membrane. Rafols et at. [13] earlier stated that the areas of disturbed Golgi ultrastructure correspond to those areas that showed evidence of lipid peroxidation.

\section{Concluding Remarks}

The pathological alterations of the Golgi complex are described in cortical biopsies of patients with congenital hydrocephalus, vascular anomaly, brain tumor and complicated brain traumatic injuries. A disruption of the Golgi elements is seen with displacement of fragmented Golgi endoplasmatic sacs, and presence of small, medium and large, clear and dense Golgi vesicles. Such images show fragmentation of the stacked Golgi cisternae, increased secretory activity in the trans-Golgi compartment, and morphological signs of increased number of Golgi and clathrin-coated vesicles with augmented intracytoplasmic vesicular traffic. In some severely edematous neurons, observed in hydrocephalus associated to Arnold-Chiari malformation, small vesicular type Golgi complexes and atrophic ones are observed, characterized mainly by partial or total disappearance of stacked Golgi cisternae and presence of congregated vesicular profiles. In brain trauma and tumors, the Golgi complex shows enlargement and fragmentation of the stacked cis- medial- and trans- Golgi cisternae and vacuolization of trans- Golgi network.

In addition, an increased formation of Golgi and coated vesicles is observed in the cis-and trans-Golgi regions. Most Golgi and clathrin-coated vesicles are observed throughout the cytoplasm suggesting an increased vesicular intracytoplsmic transport. In brain trauma, a vacuolized and hyperthrophic Golgi complex is observed in some nerve cells and endothelial cells of cortical capillaries, with increased formation of Golgi and coated vesicles. The ischemia and anoxia associated to the vasogenic and cytotoxic brain edema induce enlargement and fragmentation of stacked Golgi cisternae. The Golgi apparatus is considered an early marker of nerve cell injury, degeneration, and cell death. A vacuolized and hyperthrophic Golgi complex is observed in some nerve cells and endothelial cells of cortical capillaries, with increased formation of Golgi and coated vesicles. The ischemia and anoxia associated to the vasogenic and cytotoxic brain edema induce enlargement and 
fragmentation of stacked Golgi cisternae. The Golgi apparatus is considered an early marker of nerve cell injury, degeneration, and cell death.

\section{References}

1. Tani E, Ametani T, Nakano K, Nishiura M, Higashi N (1975) Fenestrae in Golgi and endoplasmic reticulum cisternae of human brain tumours. Acta Neuropathol 3: 13-19.

2. Tougard C, Louvard D, Picart R, Tixier Vidal A (1983) The rough endoplasmic reticulum and the Golgi apparatus visualized using specific antibodies in normal and tumoral prolactin cells in culture. J Cell Biol 96: 1197-1207.

3. Petito CK (1986) Transformation of postischemic perineuronal glial cells I. Electron microscopic studies. J Cereb Blood Flow Metab 6: 616-624.

4. Petito CK, Pulsinelli WA (1984) Sequential development of reversible and irreversible neuronal damage following cerebral ischemia. J. Neuropathol. Exp. Neurol 43: 141-153.

5. Blanchette Mackie EJ, Dwyer NK, Amende LM, Kruth HS, Butler JD, et al. (1988) Type-C Niemann-Pick disease: low density lipoprotein uptake is associated with premature cholesterol accumulation in the Golgi complex and excessive cholesterol storage in lysosomes. Proc Natl Acad Sci USA 85(21): 8022-8026.

6. Palacios G, Palacios JM, Mengod G, Frey P (1992). Beta-amyloid precursor protein localizaton in the Golgi apparatus in neurons and oligodendrocytes. An immunocytochemical structural and ultrastructural study in normal and axotomized neurons. Brain Res Mol Brain Res 15: 195-206.

7. Lucassen PJ, Ravid R, Gonatas NK, Swaab DF (1993) Activation of the human supraoptic and paraventricular nucleus neurons with aging and in Alzheimer's disease as judged from increasing size of the Golgi apparatus. Brain Res 632: 105-113.

8. Ghadially PN (1982) Golgi complex \& secretory granules. In Ultrastructural Pathlology of the Cell \& Matrix. Butterworths, London pp. 187-208.

9. Morré D (1991) Role of the Golgi apparatus in cellular pathology. J. Electron Microsc. Tech 17: 200-221.

10. Salehi A, Heyn S, Gonatas NK, Swaab DF (1995) Decreased protein synthetic activity of the hypothalamic tuberomamillary nucleus in Alzheimer's disease as suggested by smaller Golgi apparatus. Neurosci Lett 193: 29-32.

11. Stieber A, Mourelatos Z, Gonatas NK (1996) In Alzheimer's disease the Golgi apparatus of a population of neurons without neurofibrillary tangles is fragmented \& atrophic. Am J Pathol 148: 415-426.

12. Tascos N., Mourelatos Z, Gonatas NK (1995) On the significance \& reproducibility of the fragmentation of the Golgi apparatus of motor neurons in human spinal cords. J. Neuropathol Exp Neurol 54: 331-338.

13. Rafols JA, Daya AM, O Neil BJ, Krause GS, Neumar RW, et al. (1995) Global brain ischemia \& reperfusion: Golgi apparatus ultrastructure in neurons selectively vulnerable to death. Acta Neurophathol 90: 17-30.

14. Xu H, Greengard P, Gandy S (1995) Regulated formatin of Golgi secretory vesicles containing Alzheimer bet-amyloid precursor protein. J Biol Chem 270: 23243-23245.

15. Harada A, Takei Y, Kanai Y, Tanaka Y, Nonaka S, et al. (1998) Golgi vesiculation and lysosome dispersion in cells lacking cytoplasmic dynein. J Cell Biol 141: 51-59.

16. Mourelatos Z, Gonatas NK, Stieber A, Gurney ME, Dal Canto MC (1996) The Golgi apparatus of spinal cord motor neurons in transgenic mic expressing mutant $\mathrm{Cu}, \mathrm{Zn}$ superoxide dismutase becomes fragmented in early, preclinical stages of the disease. Proc Natl Acad Sci 93: 5472-5477.
17. Fujita Y, Okamoto K $0(2005)$ Golgi apparatus of the motor neurons in patients with amyotrophic lateral sclerosis \& in mice models of amyotrophic lateral sclerosis. Neuropathology 25: 388-394.

18. Fujita Y, Ohama E, Takatama M, Al Sarraj S, Okamoto K (2006) Fragmentation of Golgi apparatus of nigral neurons with alphasynuclein-ositive inclusions in patients with Parkinson's disease. Acta Neuropathol 112: 261-265.

19. Fujita Y, Watabe K, Ikeda K, Mizuno Y, Okamoto K (2011) Morphological changes of Golgi apparatus in adult rats after facial nerve injuries. Neuropathology 31(1): 42-47.

20. Greenfield JP, Tsai J, Gouras GK, Hai B, Thinakaran G, et al. (1999) Endoplasmic reticulum and trans-Golgi network generate distinct populations of Alzheimer beta-amyloid peptides. Proc Natl Acad Sci 96: 742-747.

21. Elyaman W, Yardin C, Hugon J (2002) Involvement of glycogen synthase kinase-3beta and tau phosphorylation in neuronal Golgi disassembly. J Neurochem 81: 870-880.

22. Sakurai A, Okamoto K, Fujita Y, Nakazato Y, Wakabayashi K, et al. (2000) Fragmentation of the Golgi apparatus of the ballooned neurons in patients with corticobasal degeneration and Creutzfeldt-Jakob disease. Acta Neuropathol 100: 270-274.

23. Takamine K, Okamoto K, Fujita Y, Sakurai A, Takatama M, et al. (2000) The involvement of the neuronal Golgi apparatus and trans-Golgi network in the human olivary hypertrophy. J Neurol Sci 15: 45-50.

24. Stieber A, Gonatas JO, Collard J, Meier J, Julien J, et al. (2000a) The neuronal Golgi apparatus is fragmented in transgenic mice expressing a mutant human SOD1, but not in mice expressing the human NF-H gene J Neurol Sci 173: 63-72.

25. Dubelaar EJ, Mufson EJ, Meulen WG, Van Heerikhuize JJ, Verver RW, et al. (2006). Increased metabolic activity in the nucleus basalis of meynert neurons in elderly individuals with mild cognitive impairment as indicated by the size of Golgi apparatus. J. Neuropathol Exp Neurol 65: 257-266.

26. Yaguchi M, Hashizume Y, Yoshida M, K Gonatas N, Okamoto K (2003) Reduction of the size of the Golgi apparatus of spinal anterior horn cells in patients with X-linked spinal and bulbar muscular atrophy. Amyotroph Lat, Scler Motor Neuron Disord 4: 17-27.

27. Yoshiyama Y, Zhan B, Bruce J, Trojanowski JQ Lee VM (2003) Reduction of detyrosinated microtubules \& Golgi fragmentation are linked to tauinduced degeneration in astrocytes. J Neurosci 19: 10662-10671.

28. Sahashi K, Ibi T, hno K, Sahasshi K, Nakao N, Kondo H (2004) Progressive myopathy with circulating autoantibody against giantin in the Golgi apparatus. Neurology 62: 1891-1893.

29. Moldovan L, Moldovan NI (2004) Oxygen free radicals and redox of biology of organelles. Histochem Cell Biol 122: 395-412.

30. Stieber A, Chen Y, Wei S, Mourelatos Z, Gonatas J, et al. (1998) The fragmented neuronal Golgi apparatus in amyotrophic lateral sclerosis includes the trans-Goilgi-network: functional implications. Acta Neuropathol 95: 245-253.

31. Hayashi T, Abe K (2004) Ischemic neuronal cell death \& orgenellae damage. Neurol Res 26: 827-834.

32. Grieb P, Gordon Krajcer W, Frontczak Baniewicz M, Walski M, Ryba MS, et al. (2004) 2-deoxyglucose induces beta-APP overexpression, tau hyperphosphorylation and expansion of the trans-part of the Golgi complex in rat cerebral cortex. Acta Neurobiol Exp (Wars) 64: 491-502.

33. Fujita Y, Okamoto K (2005) Golgi apparatus of the motor neurons in patients with amyotrophic lateral sclerosis \& in mice models of amyotrophic lateral sclerosis. Neuropathology 25: 388-394.

34. Ferre I, Kapfhammer JP, Hindelang C, Kemps S, Troffer Charlier N, et al. (2005) Inactivation of peroxisomal ABCD2 transporter in the mouse 
leads to late-onset ataxia involving mitochondria, Golgi and endoplasmic reticulum damage. Hum Mol Genet 14: 3565-3577.

35. Fujita Y, Ohama E, Takatama M, Al Sarraj S, kamoto K (2006) Fragmentation of Golgi apparatus of nigral neurons with alphasynuclein-ositive inclusions in patients with Parkinson's disease. Acta Neuropathol 112: 261-265.

36. Snigiresvskaia ES, Sokolova IuIa, Komissarchik IaIu (2006) Structuralfunctional organization of Golgi apparatus. Tsitologiia 48: 283-307.

37. Gonatas NK, Stieber A, Gonatas JO (2006) Fragmentation of the Golgi apparatus in neurodegenerative diseases and cell death. J Neurol Sci 246: $21-30$

38. Schaefer MK, Schmalbruch H, Buhler E, Lopez C, Martin N, et al. (2007) Progressive motor neuronopathy: a critical role of the tubulin chaperone TBCE in axonal tubulin routing from the Golgi apparatus. J Neurosci 27(33): 8779-8789.

39. Nakagomi S, Barsoum MJ, Bossy Wetzel E, Sütterlin C, Malhotra V, et al. (2008) A Golgi fragmentation pathway in neurodegeneration. Neurobiol Dis 29: 221-231.

40. Fujita Y, Watabe K, Ikeda K, Mizuno Y, Okamoto K (2011) Morphological changes of Golgi apparatus in adult rats after facial nerve injuries. Neuropathology 31: 42-47.

41. Baloyannis SJ (2014) Golgi apparatus and protein trafficking in Alzheimer's disease. J Alzheimers Dis 42 (Suppl) 3: S153-162.

42. Jaarsma D, Hoogenraad CC (2015) Cytoplasmic dynein and its regulatory proteins in Golgi pathology in nervous system disorders. Front Neurosci 9: 397.

43. Kaneko Y, Sullivan R, Dailey T, Vale FL, Tajiri N, et al. (2016) Kainic AcidInduced Golgi Complex Fragmentation/Dispersal Shifts the Proteolysis of Reelin in Primary Rat Neuronal Cells: An In Vitro Model of Early Stage Epilepsy. Mol Neurobiol 53: 1874-1883.

44. Antón Fernández A, Merchán Rubira J, Avila J, Hernández F, DeFelipe J, et al. (2017) Phospho-Tau Accumulation and Structural Alterations of the Golgi Apparatus of Cortical Pyramidal Neurons in the P301S Tauopathy Mouse Model.J Alzheimers Dis 60: 651-661.

45. Castejón OJ (1994) Transmission electron microscope study of human hydrocephlic cerebral cortex. J. Submicrosc Cytol Pathol 26: 29-39.

46. Castejón OJ, Díaz M, Valero C (1994a) Ultrastructural alterations of Golgi apparatus in the nerve cells of cerebral cortex in human hydrocephalus. A qualitative study using cortical biopsies. Scanning Microsc 8: 89-96.

47. Castejón OJ (1998). Electron microscopic analysis of cortical biopsies in patients with traumatic brain injuries \& dysfunction of neurobehavioural system. J Submicrosc Cytol Pathol 30: 145-156.

48. Stieber A, Chen Y, Wei S, Mourelatos Z, Gonatas J, et al. (1998) The fragmented neuronal Golgi apparatus in amyotrophic lateral sclerosis includes the trans-Golgi-network: functional implications. Acta Neuropathol 95: 245-253.

ISSN: 2574-1241

DOI: 10.26717/BJSTR.2018.08.001679

Orlando J Castejón. Biomed J Sci \& Tech Res

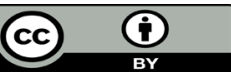

This work is licensed under Creative

Commons Attribution 4.0 License

Submission Link: https://biomedres.us/submit-manuscript.php
49. Sakurai A, Okamoto K, Fujita Y, Nakazato Y, Wakabayashi K, et al. (2000) Fragmentation of the Golgi apparatus of the ballooned neurons in patients with corticobasal degeneration and Creutzfeldt-Jakob disease. Acta Neuropathol 100: 270-274.

50. Thorne Tjomsland G, Jamieson JC (1995) Changes in the morphology and phosphatase cytochemistry of the Golgi region of hepatocytes during the acute phase response to inflammation. Anat Rec 241: 439-450.

51. Misteli T (1996) Molecular mechanisms in the disassembly \& reassembly of the mammalian Golgi apparatus during M-phase. FEBS Lett 389(1): 66-69.

52. Bainton DF, Takemura R, Sternberg PE, Werb Z (1989) Rapid fragmentation and reorganization of Golgi membranes during frustrated phagocytosis of immobile immune complexes by macrophages. Am J Pathol 134(1): 115-26.

53. Castejón OJ, Valero C, Díaz M (1997) Light \& electron microscope study of nerve cells in traumatic oedematous human cerebral cortex. Brain injury 11(5): 363-388.

54. Castejón OJ, Valero C, Díaz M (1994) Ultrastructural alterations of Golgi Aparatus in the nerve cells of cerebral cortex in human hydrocephalus. A qualitative study using cortical biopsies. Scanning Microscopy 8(1): 89-96.

55. Castejón OJ (1999) Ultrastructural pathology of Golgi apparatus of nerve cells in human brain edema associated to brain congenital malformations, tumours and trauma. J Submicrosc Cytol Pathol. 31(2): 203-213.

56. Castejón OJ, Castejón HV, Diaz M, Castellano A (2001) Consecutive light microscopy, scanning-transmission electron microscopy and transmisión electron microscopy of traumatic human brain oedema and ischaemic brain damage. Histol Histopathol 16(4): 1117-1134.

57. Spuler A, Tan WKM, Meyer FB (1996) Molecular events in cerebral ischemia. In: The Molecular Basis of Neurosurgical Disease. In: Raffels C, Harsh GR (Eds.) William \& Wilkins Baltimore: 248-269.

58. André KH (1964) Micropinocytose in Zentralnerven System. Z Zellforsch 64: 63-73.

59. Gray EG (1970) The question of relationship between Golgi vesicles \& synaptic vesicles in Optopus neurons. J Cell Sci 7(1): 189-201.

60. Ginsberg MD, Watson BD, Bustos R, Yoshida S, Prado R, et al., (1988) Peroxidative damage to cell membrane following cerebral ischemia. A cause of ischemic brain injury. Neurochem Pathol 9: 171-193.

61. Mc Cord JM (1985) Oxygen-derived free radicals in post-ischemic tissue injury. N Engl J Med 312(3): 159-163.

62. Novicki JP, Duval D, Poigner H, Scatton B (1991) Nitric oxide mediates neuronal death after focal cerebral ischemia in the mouse. Eur J Pharmacol 204(3): 339-340.

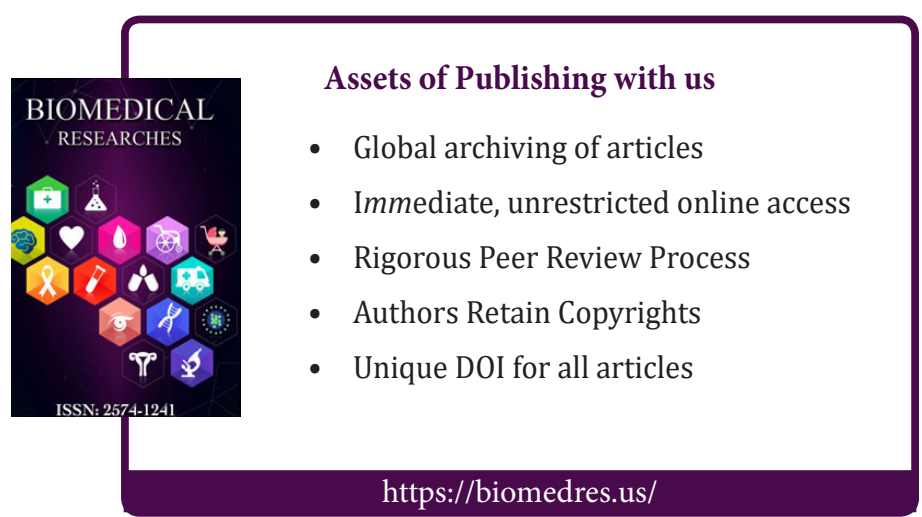

